\title{
Effect of Di-ammonium Hydrogen Phosphate on Jute Fabric for Fire Resistance
}

\author{
Ayesha Khatton ${ }^{1}$, Mubarak Hossen ${ }^{1,}$, , Nayer Sultana ${ }^{2}$, Mohammad Lutful Ahsan ${ }^{3}$ \\ ${ }^{1}$ Chemistry Division, Bangladesh Jute Research Institute, Dhaka, Bangladesh \\ ${ }^{2}$ Pilot Plant and Processing Division, Bangladesh Jute Research Institute, Dhaka, Bangladesh \\ ${ }^{3}$ Chemistry Department, Cumilla Residential College, Cumilla, Bangladesh
}

Email address:

mbmubarak24@gmail.com (M. Hossen)

${ }^{*}$ Corresponding author

\section{To cite this article:}

Ayesha Khatton, Mubarak Hossen, Nayer Sultana, Mohammad Lutful Ahsan. Effect of Di-ammonium Hydrogen Phosphate on Jute Fabric for Fire Resistance. Science Journal of Energy Engineering. Vol. 7, No. 4, 2019, pp. 63-66. doi: 10.11648/j.sjee.20190704.12

Received: September 15, 2019; Accepted: October 15, 2019; Published: October 25, 2019

\begin{abstract}
Over the years, technologies have been used for the development of various textile products to meet the consumer demands in different fields as per their end-use specifications. The market sustainability of each new product mainly depends on the raw material as well as its functionality. A functional finishing dictates the end-use of the products as well as enhances the life of the products. There are important historical and economic reasons for the fact that, the science and technology of flame retardant for cellulose fibres are more advanced than for other fibres and polymers. Until perhaps 25 years ago, an overwhelming proportion of all textiles used were made of cellulose fibres. Jute is one of the important natural cellulosic fibers and used for diversified product. Similar to cotton, jute fiber has the potential to impart different functionality by different chemical finishing for its diversification. This project has been taken to improve the flameproof property of jute fabrics. Jute fabrics were treated with Di-Ammonium Hydrogen Phosphate by various concentrations under certain condition. The study was conducted at the Industrial Chemistry Department, Chemistry Division, Textile Physics Division and Pilot Plant and Processing Division of Bangladesh Jute Research Institute, Dhaka, Bangladesh during 2017-2019. It was found that desized jute fabric gives the best flame proofed (Completely resistance to both after flaming and after glowing) than the sized jute fabrics without undesirable loss of the tensile strength.
\end{abstract}

Keywords: Jute Fabric, Flameproof, Desized, Scouring, Retardant

\section{Introduction}

Jute is the main cash crop of Bangladesh for its unique properties like high strength, rough handling and environment friendly. Jute industry is the main economic wealth of Bangladesh [1]. Once jute was only used as packaging. Beside this, due to inroads of synthetics, the use of jute as packaging materials has been decreased [2]. This century is called industrialization century. The challenge for this century is to find out the new ways to produce cost effective diversified value added products. Fire-proof process is one of the treatment processes for jute diversified uses. For example, flame protective clothing for fire fighter's suit, foundry workers, and military aviation and space personnel and for other industrial workers who are exposed to hazardous conditions. Major challenges to coatings and fabrication technology for production in the flame-retardant textile industry have been to produce environmentally friendly, non-toxic flame-retardant systems that complement the comfort properties of textiles. [3-6]. A large number of works were done on fire proofing of cotton. But very few works on fireproofing of jute are found. Some of the important works on fire proofing process are as follows:

The bromination process for fire-proofing of timber [7] was first developed by the "Institute of fibre and forest products" of the Ministry of Commerce \& Industry in Israel. The same process when applied to vegetable fibres including the lignocellulosic fibres like jute gives similar effect without impairing the tensile strength of the fibre material. [8] reported that ammonium salts of bromine, chlorine and iodine are effective in the prevention of after flaming and 
phosphoric acid \& its sodium and ammonium salts are effective in the prevention of after glowing of the textile fabrics [9]. They observed that bromination of jute imparts a fire- resistance property which is handicapped by excessive after glowing and some strength loss. [10] reported that phosphoric acid is highly effective in flame proofing of the cellulosic materials. Cotton fabric was used for flameresistance products for a longtime. But recently we take this project to produce flame proof jute fabrics for reduce the pressure of cotton and at the same time we need Diammonium hydrogen phosphate as a flame proofing agent. This study was designed to find out textile finishing and proofing process for imparting flameproof finishes to jute fabric for diversified textile uses of jute.

\section{Materials and Methods}

The experiment was conducted at the Bangladesh Jute Research Institute, Dhaka, Bangladesh.

Experimental sample: Jute fabric (13.8 pick/inch, 15.4 end/ inch) was collected from the local market, Bangladesh. Thirteen sample specimens of 16-inchs width and 70-inch length were prepared from the above mentioned sample.

Chemicals:

Commercial grade Di-ammonium Hydrogen phosphate $\left[\left(\mathrm{NH}_{4}\right)_{2} \mathrm{HPO}_{4}\right]$

Diastage, Sodium carbonate, Sodium Hydroxide, wetting agent, Phosphoric acid, Lissapol. All chemicals were reagent grade except Di-ammonium Hydrogen phosphate.

Machine:

In this experiment we used different types of machine. These are Digital electronic Balance, $\mathrm{P}^{\mathrm{H}}$ meter, Padding machine, Laboratory stenter machine, water bath, Different glassware, Tensile strength tester, Jigger machine and auxiliaries etc.

Padding machine (2b/press) was used for uniform distribution of proofing ingredients in the fabric.

Heat setting machine was used for drying and heat setting purpose. It was then calendered and hot pressed to achieve better stiffing along with smooth finishing effect.

Methodology:

In this work, we had been used two types of fabrics, these are: Sized and Desized jute fabrics.

Desizing: Desizing was done with 2-3 gm/lit with diastase at temperature of $50^{\circ}-60^{\circ} \mathrm{C}$ for 45 minutes [11-12] bearing liquor ratio 1:20 then washed with water and dried at ambient temperature.

Scouring: To remove the dirt, wax, oil and fatty acids from the fabric. Firstlyfabric was scoured by standard method with a solution of $3 \%$ sodium carbonate, $1 \%$ sodium hydroxide, $1 \%$ wetting agent at $80^{\circ}-90^{\circ} \mathrm{C}$ in bath for one hour bearing liquor ratio 1:20. It was then washed with water and dried at ambient temperature [11-12].

Twelve samples (sized and desized) were treated with different concentration of Di-ammonium hydrogen phosphate solution $(20 \%, 25 \%, 30 \%, 35 \%, 40 \% \& 45 \%)$ in a minipadding machine

Liquor pick-up: The liquor pick up was determined for each of the samples. The liquor pick up of the treatment process was determined by weight of samples before padding and after padding according to the following formula;

Liquor pick up $=($ weight of sample after padding - weight of sample before padding) X 100/weight of sample before padding.

Flame test: The Flame test was performed by the vertical Spread method of Flame Test. The vertical flame test is the most severe test. The criteria evolutions are char length, after flame removal and after vanishing of glow. Fabric specimen dimensions are $1.5^{*} 72 \mathrm{in}$, conditioned at $70^{\circ} \mathrm{F}$ and $65 \%$ relative humidity. The specimen mounted in a holder kept in a cabinet, is subjected to standard flame (gas burner) at its lower edge, under controlled condition. The fabric specimen is suspended in a vertical position and flame is applied along the fabric width. The rate of sample spread is recorded and the flaming time, after glow time and char lengths are measured [13-15].

Tensile strength: the tensile strength of the treated samples was measured by the standard method (Booth, 1996). Room temperature was maintained as follows: Temp $=20^{\circ} \pm 2^{\circ} \mathrm{C}$, Humidity $=65 \% \pm 2 \%$.

Storage test: Effect of storage on the flame proofness and tensile strength of the treatment fabrics were observed up to three months.

\section{Results and Discussion}

Size and desized jute fabrics were treated with flame proof solution of selected fire retardant chemicals under certain condition. The experimental results are shown in the table 1 and table 2 .

Table 1. Flame test of size fabrics.

\begin{tabular}{|c|c|c|c|c|c|c|c|}
\hline \multirow{2}{*}{ SI No. } & \multirow{2}{*}{$\begin{array}{l}\text { Cons of sol } \\
(\%)\end{array}$} & \multirow{2}{*}{$\begin{array}{l}\text { Liquor pick up } \\
(\%)\end{array}$} & \multirow{2}{*}{$\begin{array}{l}\text { Curing Temp. } \\
\left({ }^{\circ} \mathrm{C}\right)\end{array}$} & \multirow{2}{*}{$\begin{array}{l}\text { Curing time } \\
\text { (min) }\end{array}$} & \multicolumn{3}{|c|}{ Vertical Bunsen burner flame test } \\
\hline & & & & & After flame (sec) & After glow(sec) & Char length (inch) \\
\hline 01 & 20 & 105 & 180 & 02 & 00 & 02 & 2.1 \\
\hline 02 & 25 & 107 & 180 & 02 & 00 & 01 & 1.6 \\
\hline 03 & 30 & 110 & 180 & 02 & 00 & 00 & 0.9 \\
\hline 04 & 35 & 110 & 180 & 02 & 00 & 00 & 1.4 \\
\hline 05 & 40 & 106 & 180 & 02 & 00 & 02 & 1.8 \\
\hline
\end{tabular}


Table 2. Flame test of Desized fabrics.

\begin{tabular}{|c|c|c|c|c|c|c|c|}
\hline \multirow{2}{*}{ SI No. } & \multirow{2}{*}{$\begin{array}{l}\text { Cons of sol } \\
(\%)\end{array}$} & \multirow{2}{*}{$\begin{array}{l}\text { Liquor pick up } \\
(\%)\end{array}$} & \multirow{2}{*}{$\begin{array}{l}\text { Curing Temp. } \\
\left({ }^{\circ} \mathrm{C}\right)\end{array}$} & \multirow{2}{*}{$\begin{array}{l}\text { Curing time } \\
\text { (min) }\end{array}$} & \multicolumn{3}{|c|}{ Vertical Bunsen burner flame test } \\
\hline & & & & & After flame (sec) & After glow(sec) & Char length (inch) \\
\hline 01 & 20 & 105 & 180 & 02 & 00 & 00 & 0.6 \\
\hline 02 & 25 & 107 & 180 & 02 & 00 & 00 & 0.5 \\
\hline 03 & 30 & 110 & 180 & 02 & 00 & 00 & 0.4 \\
\hline 04 & 35 & 110 & 180 & 02 & 00 & 00 & 0.4 \\
\hline 05 & 40 & 106 & 180 & 02 & 00 & 01 & 0.6 \\
\hline
\end{tabular}

Table 3. Effect of storage on the properties of flameproofness and tensile strength of the treated fabric.

\begin{tabular}{|c|c|c|c|c|}
\hline \multirow{2}{*}{ Storage period (days) } & \multicolumn{3}{|c|}{ Vertical Bunsen burner flame test } & \multirow{2}{*}{ Loss of tensile strength $(\%)$} \\
\hline & After flame (sec) & Afterglow (sec) & Char length (inch) & \\
\hline 0 & 00 & 00 & 0.4 & 9.72 \\
\hline 15 & 00 & 00 & 0.4 & 9.75 \\
\hline 30 & 00 & 00 & 0.5 & 9.90 \\
\hline 45 & 00 & 00 & 0.5 & 9.95 \\
\hline 60 & 00 & 00 & 0.6 & 10.10 \\
\hline 90 & 00 & $0-2$ & 0.9 & 10.40 \\
\hline
\end{tabular}

According to current practices, Textile fabric is regarded as flame proofed if after removal of the source of flame applied to the fabric for 12-13 seconds, the flaming of the fabric (after flame) does not continue even for a single second, the flameless combustion (after glow) continues for less than 4 seconds and the char length does not occur for more than 3.5 inches.

During the treatment of jute fabrics with di-ammonium hydrogen phosphate it was observed that with increased ratio of chemicals the after flame and afterglow remained same but char length of flame test decreased (table 1 and table 2). After a certain point increase in ratio of chemicals result in increase of the char length.

By comparing the results in the table 1 and table 2, it is observed that treated desized fabric gives better flame test result than sized fabric. And desized fabrics treated at $30 \%$ chemical concentration gives the best flame proof results amongst the other entire sample.

Finally the treatment method developed can be used to achieve the desired level offlame proofing but it is not sufficiently fast to washing. The effectiveness of the treatment reduces considerably upon storage. There is also gradual loss of tensile strength (table 3 ).

\section{Conclusion}

In this study, the effects of Di-ammonium hydrogen phosphatewith varying concentrations were observed on the flame retardancy of $100 \%$ jute fabrics. Satisfactory flame retardancy was achieved through chemical treatment with some loss of tensile strength. The tensile strength further decreases with store time. Further work is being continued to impart better fire resistant property to the fabrics.

\section{References}

[1] Abul Kassem, A. B. M. 1992. "Jute and its Diversification" Firstpublished, March 1992 Publisher: Mrs. Hosene Ara Kassem P2]rinted By: Kathamala Mudrayan, 8/A, Babupura, Nilkhet, Dhaka-1205, P. 4.

[2] Mohammad Ali (1985). Modification and Jute fibre and fabrics Bangladesh, Vol, 11 No. 9\&10, P. 20.

[3] Anonymous, 1997. Environmental and safety focus, Textile. Month-April 1997, 37.

[4] BTTU, 1991. Burning issues- Environmentally friend her flame retardant systems, Int. Dyer, Oct. 1991. P; 17-20.

[5] Roberts, D. L., M. E. Hall and A. R. Horrocks. 1992. Environmental aspects of flame retardant textiles- an overview, Rev. Prog. Col., 1992224857.

[6] Carrull, T. 1997. Revitalizing the market for safety apparel with high performance disposables, Tech. Textiles Int. Nov. $199717-21$

[7] Anonymous, (1965) Jute \& Canvas review, U.S.A., XXXVI 437, Feb. 65. Fire-proofingjute.

[8] Little, R. W. 1947. Flame proofing Textile fabrics, American Chemical Society Monograph series.

[9] Sengupta, Sangram, R. 1975. Bromination of jute fabrics. Indian Jute Ind. Res. association, Calcutta, India Colourage 1975, 22(18), 35-8 (Eng). Chemical Abstract. 83: 194979h.

[10] Tyuganova, M. A., Rogovin Z. A., Kryazhv (1978). Fireresistant cellulose materials Chemical Abstract. 78: 5639k.

[11] March, J. T. 1996. Chapman and hall, London, An introduction to textile finishing.

[12] Trotman, E. R. 1968. Griffin, London. Textile scouring and bleaching. 
[13] Lewin, M., Atlas, S. A., pearce, E. M.: Flame- Retardant Polymeric Materials, vol. 1, Plenum Press, New York (1978).

[14] Hebeish, A., Tuthrice, J. T.: The Chemistry and Technology of Cellulose Copolymers. Springer, Berlin (1981).
[15] AATCC Test Method (1934-1969), vertical burning tests method in fire resistance of textile fabrics. Technical Manual Method of the American Association of textile Chemist and Colorists, USA. P: 201-202 (1972). 